\title{
Commotio cordis without arrhythmic event and resuscitation: ECG, echocardiographic, angiographic and cardiovascular resonance imaging study
}

\author{
Giorgio Maringhini, ${ }^{1}$ Sergio Fasullo, ${ }^{1}$ Gabriella Vitrano, ${ }^{1}$ Gabriella Terrazzino, ${ }^{1}$ Filippo Ganci, ${ }^{1}$ \\ Salvatore Paterna, ${ }^{2}$ Pietro Di Pasqual ${ }^{1}$
}

${ }^{1}$ Department of Cardiology, G.F. Ingrassia Hospital, Palermo, Italy

2Department of Emergency Medicine, University of Palermo, Italy

Correspondence to Pietro Di Pasquale, lehdi@tin.it

\begin{abstract}
Summary
We describe a case of commotio cordis in which the patient had an extensive cardiac evaluation, including ECGs, a coronary angiogram, a left ventriculogram, repeated echocardiography and cardiovascular MRI (CMRI). A healthy 17-year-old boy sustained an open-handed blow to the anterior part of the chest from a friend with whom he was playing. On admission ECG was performed that showed ST-T alterations and a TNI increase, with echocardiographic evidence of a localised pericardial effusion associated with a persistent myocardial blush at selective angiography. In addition, CMRI confirmed a local delayed enhancement in the same zone. An echocardiogram examination performed 30 days after discharge showed a complete disappearance of pericardial effusion and an improvement on ECG alterations. This is the first case report of a patient with commotio cordis, who did not show any arrhythmias and did not receive any resuscitation procedure, and was extensively studied by imaging methods.
\end{abstract}

\section{BACKGROUND}

One of the most increasingly reported causes of sudden cardiac death in young adults is that of commotio cordis. This phenomenon may be a 'pure' instance of mechanically induced arrhythmia. With the increased awareness of this condition over the last years, the number of reported cases of commotio has dramatically risen. The Commotio Cordis Registry has over 130 patients and approximately 10 new cases are reported each year. ${ }^{1}$ Still, it is probable that the actual number of cases is greater than reported because of the lack of awareness of this devastating condition and underreporting to the Commotio Cordis Registry. Collapse in most cases is immediate, although some report up to a minute of presyncope prior to collapse. At autopsy, no acute or chronic cardiac pathology, or damage to the ribs, sternum or heart have been found that would account for the sudden death. An absence of structural cardiac injury distinguishes commotio cordis from cardiac contusion, in which high-impact blows result in traumatic damage to myocardial tissue and the overlying thorax.

Commotio cordis occurs primarily in children, adolescents and young adults, most often during participation in certain recreational or competitive sports, with rare occurrences during normal, routine daily activities. ${ }^{1-8}$ We describe a case of commotio cordis in which the patient had an extensive cardiac evaluation, including ECGs, a coronary angiogram, a left ventriculogram, repeated echocardiography and cardiovascular MRI (CMRI). These clinical details suggest that the mechanism of commotio cordis may be more complex than solely ventricular fibrillation.

\section{CASE PRESENTATION}

A healthy 17-year-old boy sustained an open-handed blow to the anterior part of the chest from a friend with whom he was playing. The patient, $4 \mathrm{~h}$ after the chest blow, complained of chest pains with resolution by paracetamol consumption. Owing to the recurrence of chest pain he underwent medical control and thorax $\mathrm{Rx}$ which did not reveal any thoracic alteration. The following day the patient continued to complain of thorax discomfort and was referred to our emergency department. On admission ECG showed ST-T alterations (figure 1). In addition, troponin I (TNI) plasma determination showed a significant increase $(18 \mathrm{pg} / \mathrm{ml})$ and the patient was hospitalised in the coronary care unit (CCU). On admission to the CCU an echocardiogram was performed and it showed a localised pericardial effusion (inferior-posterior) and complete absence of segmentary kinetic alterations (figure 1). Serial ECGs, and echocardiography, during hospitalisation, showed ST-T changes and localised pericardial effusion as diagnosed at entry to the emergency department, while laboratory analysis revealed a TNI increase $(30 \mathrm{pg} / \mathrm{ml})$. No arrhythmic event was observed. In addition, all the laboratory parameters were in normal range, also including inflammatory indices (high sensitivity $\mathrm{C}$ reactive protein, white blood cell count, erythrocyte sedimentation rate, etc). Anti-inflammatory treatment (indomethacin $50 \mathrm{mg}$ twice daily) was immediately started, but $12 \mathrm{~h}$ after admission the patient continued to complain of chest pains. For this reason a thoracic spiral CT was performed, which did not show any pulmonary vascular or lung damage. About 30 min after the spiral CT the patient showed an increase in chest pain; however, the echocardiogram remained 


\section{BMJ Case Reports}
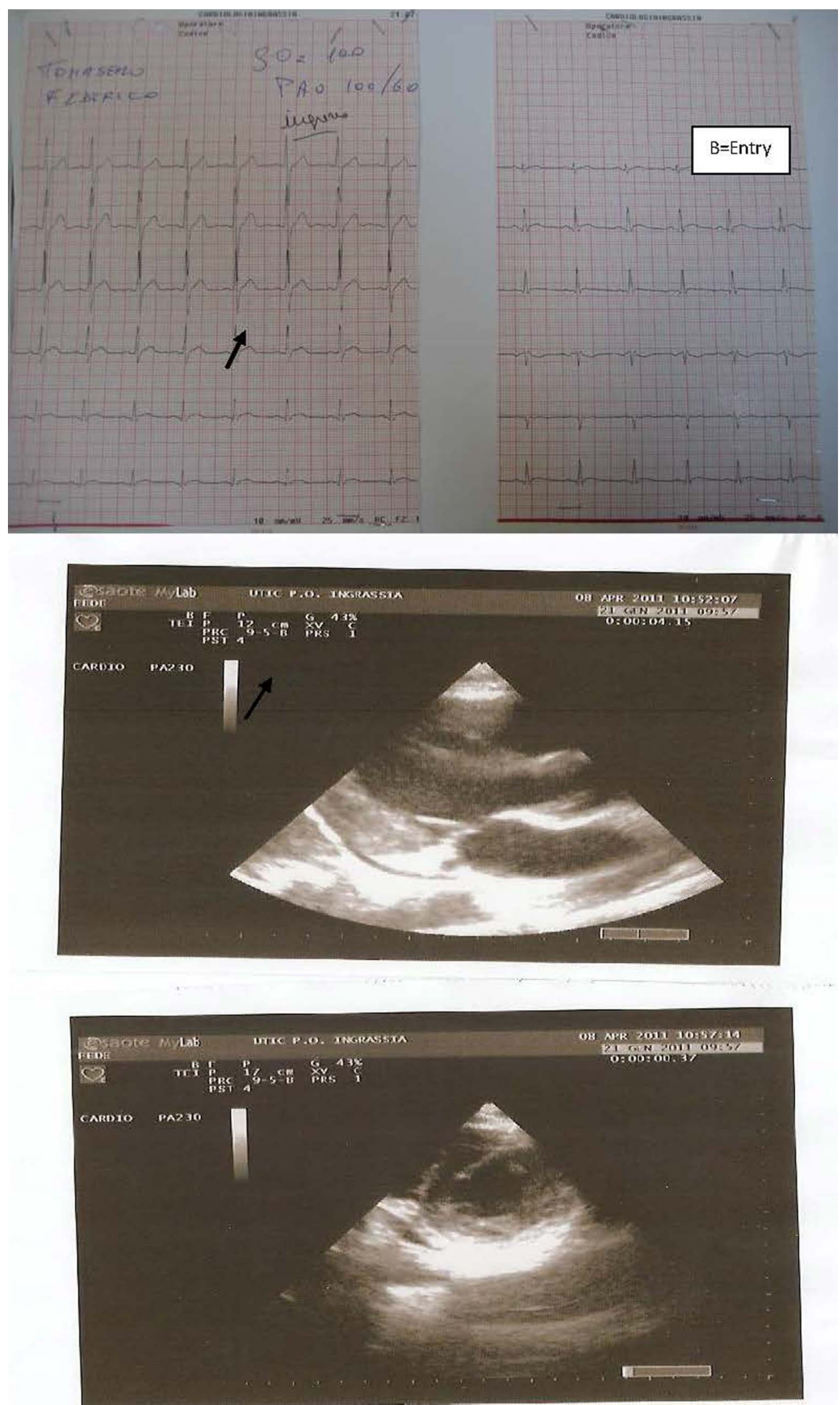

Figure 1 (A) Echocardiogram on admission. (B) ECG on admission.

unmodified whereas the ECG showed an increase in ST-T alterations (figure 2). Under the assumption that coronary damage had occurred, a coronary and left ventricle angiography was performed. The coronary tree was normal, while the selective angiography of the right coronary showed an important delayed and persistent myocardial blush in the inferior-posterior zone, on the same side as the pericardial effusion revealed by the echocardiogram (figure 3). After the coronary angiography and analgesic administration the chest pain ceased completely and the ECG 

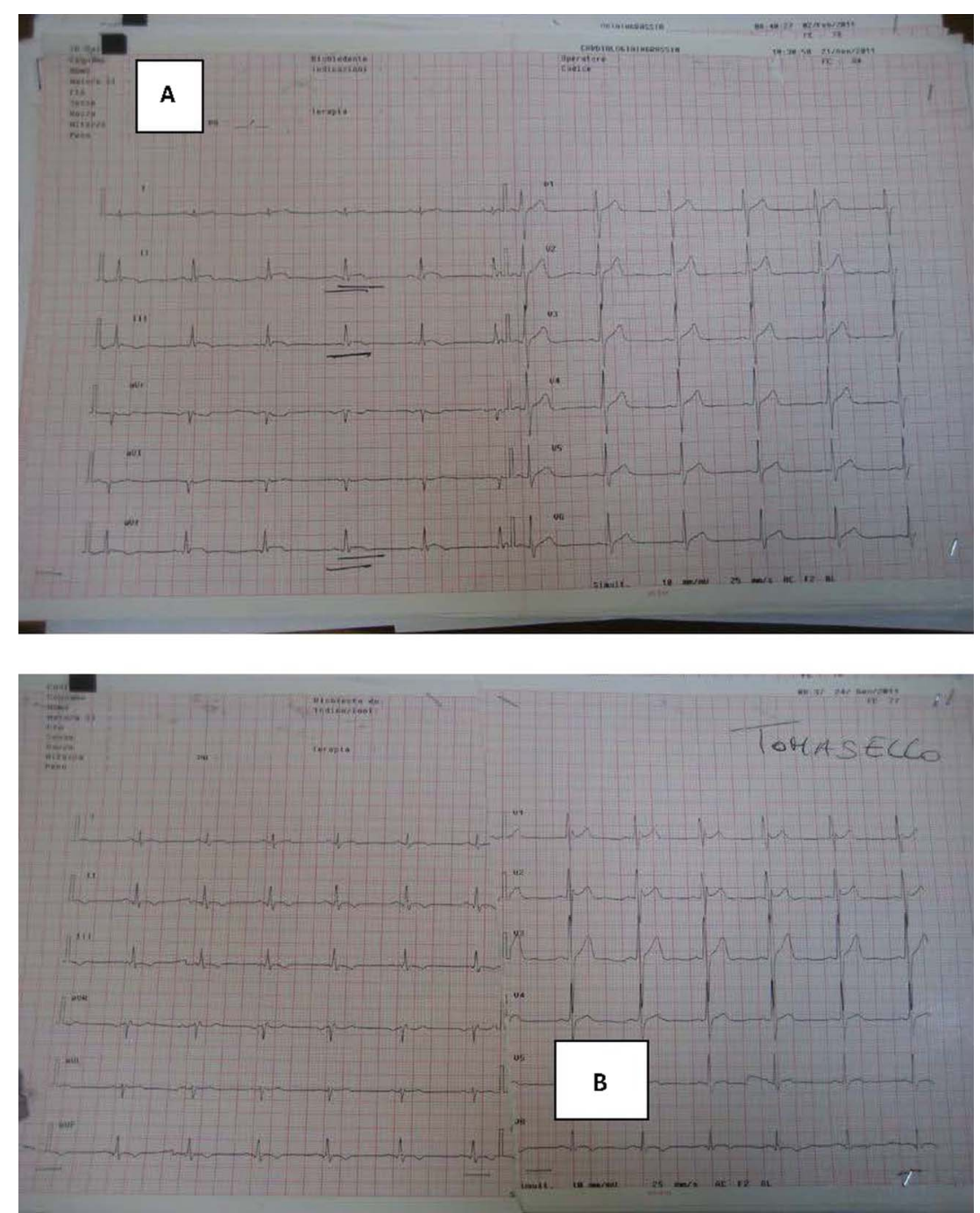

Figure 2 (A) ECG during chest pain and before coronary angiography. (B) ECG postcoronary angiography.

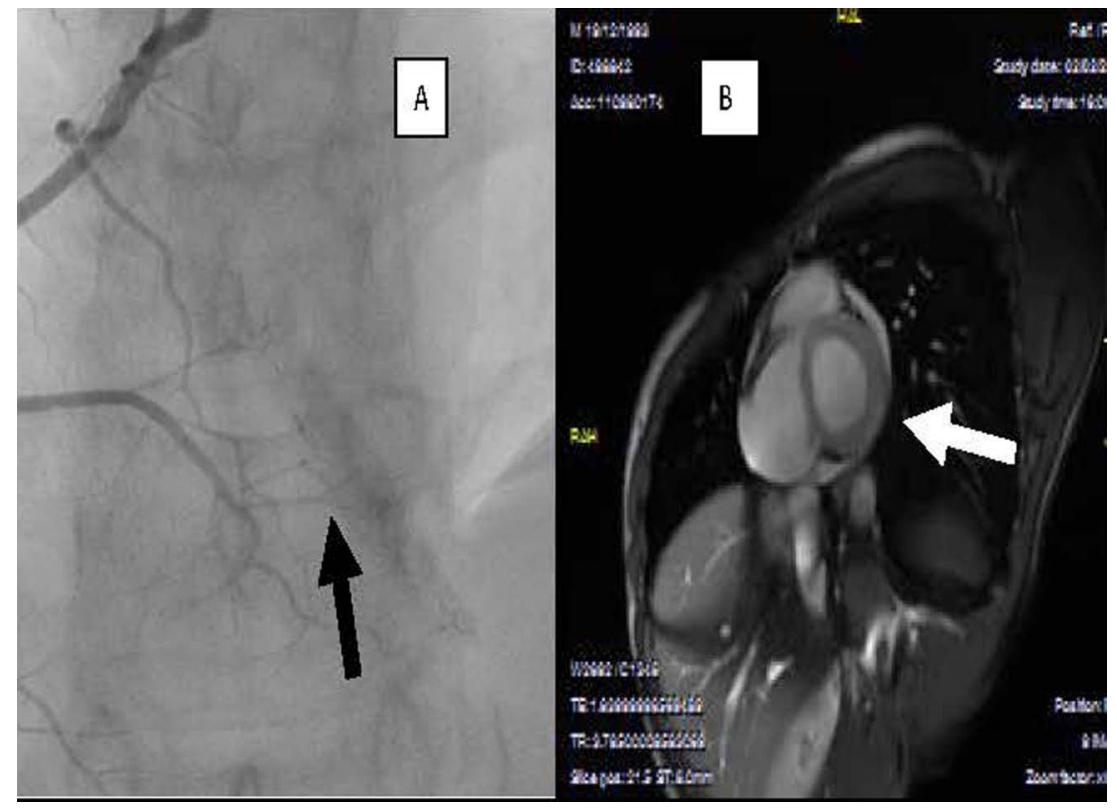

Figure 3 (A) Myocardial blush regarding right coronary territory and (B) predischarge, cardiovascular MRI. 
showed $\mathrm{T}$-wave inversion in inferior leads (figure 2). The patient continued anti-inflammatory treatment without any problem in the subsequent days, and 4 days after admission normalisation in TNI plasma levels was observed associated with a reduction of the localised pericardial effusion diagnosed on entry. Before discharge (7 days after admission), in order to obtain a thorough understanding of the patient's condition a cardiovascular CMRI (figure 3) was performed. The CMRI showed a persistent local delayed enhancement in the inferior-posterior myocardial wall, and this finding was in line with the evidence of myocardial blush and the pericardial effusion observed by echocardiography in this zone. The ECG and the echocardiogram control performed 30 days after discharge showed the complete disappearance of pericardial effusion and an improvement on ECG alterations.

\section{Learning points}

- Recent experimental laboratory studies conducted under controlled conditions with pigs, dogs and rabbits, ${ }^{9-13}$ have provided insights into the underlying mechanisms of commotio cordis that are consistent with its clinical profile and have dispelled the notion that sudden death after a blow to the chest is a mysterious phenomenon. ${ }^{12}$

- The cellular (and subcellular) mechanisms responsible for commotio cordis appear to be multifactorial and complex, and they remain incompletely defined. Information obtained from experimental and animal models ${ }^{13-17}$ has led to hypotheses concerning specific mechanistic pathways. It is believed that the mechanical force generated by precordial blows during repolarisation causes left ventricular intracavitary pressure. ${ }^{10} 141518$

- It has been hypothesised that this elevation in pressure causes the cell membranes to stretch, activating ion channels and increasing transmembrane current flow by means of mechanical-electric coupling. ${ }^{9} 101316$ Autopsies on commotio cordis victims are notable for the lack of coronary artery damage, coronary artery thrombosis or myocardial infarction. ${ }^{2}{ }^{12}$ Another possibility is that myocardial contusion causes the ECG and clinical abnormalities. However, despite frequent ECG abnormalities and contusions in animal models of chest wall trauma, ventricular fibrillation is only rarely seen. ${ }^{19}$ In human commotio cordis victims, occasional myocardial haemorrhage is seen, but it is never extensive and is usually ascribed to resuscitation efforts. ${ }^{2}$ This case report gives a rare glimpse into the pathophysiological characteristics of commotio cordis because of the relatively complete and serial studies of the patient's cardiac anatomy and physiological features. Clinically the description of the patient is typical of previous descriptions of commotio cordis victims. He is young and healthy, but did not have sudden cardiac death following the chest wall trauma. In this patient who did not present any arrhythmic event and received no resuscitation procedure, the ECG, echocardiographic, angiographic and cardiovascular MRI (CRMI) findings all suggest that the sudden death in commotio cordis for ventricular fibrillatory arrest could also have other causes.
Prolonged ST-T abnormalities are unusual in a primary ventricular fibrillation arrest and ST-T abnormalities would be more common with myocardial ischaemia or myocardial contusion. Similarly, although ventricular fibrillation frequently causes transient global hypokinesis, a regional, reversible wall motion abnormality would be more commonly associated with transient myocardial ischaemia or myocardial contusion. In this case report, even if localised pericardial effusion, late and persistent myocardial blush and persistent and delayed enhancement were present, no wall motion abnormality was observed. This case may also provide some explanation for the high mortality of commotio cordis victims. The ECG, echocardiographic, coronary angiography, CRMI and TNI findings suggest that in patients with commotio cordis a small local myocardial injury can be verified by intrawall bleeding that may trigger fatal arrhythmias.

- In conclusion, the clinical details of this case suggest that commotio cordis is more complex than a primary ventricular fibrillatory arrest and that myocardial contusion may also play a role. This is the first case report of a patient with commotio cordis who did not show any arrhythmias and where no resuscitation was required. Clearly, more information is needed to delineate the cause and pathophysiological findings of commotio cordis.

\section{Competing interests None}

Patient consent Obtained.

\section{REFERENCES}

1. Maron BJ, Gohman TE, Kyle SB, et al. Clinical profile and spectrum of commotio cordis. JAMA 2002;287:1142-6.

2. Maron BJ, Poliac L, Kaplan JA, et al. Blunt impact to the chest leading to sudden death from cardiac arrest during sports activities. N Engl J Med 1995; 333:337-42.

3. Nesbitt AD, Cooper PJ, Kohl P. Rediscovering commotio cordis. Lancet 2001:357:1195-7.

4. Zangwill SD, Strasburger JF. Commotio cordis. Pediatr Clin North Am 2004:51:1347-54.

5. Boden BP, Tacchetti R, Mueller FO. Catastrophic injuries in high school and college baseball players. Am J Sports Med 2004;32:1189-96.

6. Maron BJ. Sudden death in young athletes. N Engl J Med 2003:349:1064-75

7. Maron BJ, Doerer JJ, Haas TS, et al. Sudden deaths in young competitive athletes: analysis of 1866 deaths in the United States, 1980-2006. Circulation 2009;119:1085-92.

8. Maron BJ, Doerer JJ, Haas TS, et al. Commotio cordis and the epidemiology of sudden death in competitive lacrosse. Pediatrics 2009;124:966-71.

9. Kohl P, Nesbitt AD, Cooper PJ, et al. Sudden cardiac death by commotio cordis:role of mechano-electric feedback. Cardiovasc Res 2001:50:280-9.

10. Bode F, Franz MR, Wilke I, et al. Ventricular fibrillation induced by stretch pulse: implications for sudden death due to commotio cordis. J Cardiovasc Electrophysiol 2006;17:1011-17.

11. Cooper GJ, Pearce BP, Stainer MC, et al. The biomechanical response of the thorax to nonpenetrating impact with particular reference to cardiac injuries. $J$ Trauma 1982;22:994-1008.

12. Liedtke AJ, Allen RP, Nellis SH. Effects of blunt cardiac trauma on coronary vasomotion, perfusion, myocardial mechanics, and metabolism. J Trauma 1980;20:777-85.

13. Madias C, Maron BJ, Supron S, et al. Cell membrane stretch and chest blow-induced ventricular fibrillation (commotio cordis). J Cardiovasc Electrophysiol 2008;19:1304-9. 
14. Link MS, Wang PJ, VanderBrink BA, et al. Selective activation of the $\mathrm{K}+$ ATP channel is a mechanism by which sudden death is produced by low energy chest wall impact (commotio cordis). Circulation 1999;100:413-18.

15. Link MS, Maron BJ, Wang PJ, et al. Upper and lower limits of vulnerability to sudden arrhythmic death with chest wall impact (commotio cordis). J Am Coll Cardiol 2003;41:99-104.

16. Garan AR, Maron BJ, Wang PJ, et al. Role of streptomycin sensitive stretch activated channel in chest wall impact induced sudden death (commotio cordis). J Cardiovasc Electrophysiol 2005;16:433-8.
17. Stout CW, Maron BJ, Vanderbrink BA, et al. Importance of the autonomic nervous system in an experimental model of commotio cordis. Med Sci Monit 2007;13:BR11-15

18. Link MS, Maron BJ, VanderBrink BA, et al. Impact directly over the cardiac silhouette is necessary to produce ventricular fibrillation in an experimental model of commotio cordis. J Am Coll Cardiol 2001;37: 649-54.

19. Bright EF, Beck CS. Nonpenetrating wounds of the heart: a clinical and experimental study. Am Heart J 1935;10:293-321.

Copyright 2012 BMJ Publishing Group. All rights reserved. For permission to reuse any of this content visit http://group.bmj.com/group/rights-licensing/permissions.

BMJ Case Report Fellows may re-use this article for personal use and teaching without any further permission.

Please cite this article as follows (you will need to access the article online to obtain the date of publication).

Maringhini G, Fasullo S, Vitrano G, Terrazzino G, Ganci F, Paterna S, Di Pasqual P. Commotio cordis without arrhythmic event and resuscitation: ECG, echocardiographic, angiographic and cardiovascular resonance imaging study. BMJ Case Reports 2012;10.1136/bcr-03-2011-3968, Published XXX

Become a Fellow of BMJ Case Reports today and you can:

- Submit as many cases as you like

- Enjoy fast sympathetic peer review and rapid publication of accepted articles

- Access all the published articles

- Re-use any of the published material for personal use and teaching without further permission

For information on Institutional Fellowships contact consortiasales@bmjgroup.com

Visit casereports.bmj.com for more articles like this and to become a Fellow 